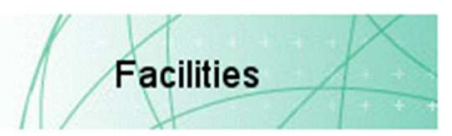

\title{
Effect of Facilities Management Components on the Quality of Life of Chinese Elderly in Care and Attention Homes
}

\begin{tabular}{|r|l|}
\hline Journal: & Facilities \\
\hline Manuscript ID & f-03-2016-0032.R1 \\
\hline Manuscript Type: & Original Article \\
\hline Keywords: & $\begin{array}{l}\text { Facilities management, Care and attention homes, Elderly, Quality of life, } \\
\text { Housing, Chinese }\end{array}$ \\
\hline \multicolumn{2}{|c}{} \\
\hline
\end{tabular}




\title{
Effect of Facilities Management Components on the Quality of Life of Chinese Elderly in Care and Attention Homes
}

\begin{abstract}
Purpose: Quality of life (QoL) for elderly residents of care and attention (C\&A) homes has become an important consideration given the increasingly aging population. Due to the number of hours such residents spend indoors, the quality of the facilities can contribute to their day to day QoL. This study investigates the effect of facilities management (FM) on the QoL of Chinese elderly people living in C\&A homes.

Design/Methodology/Approach: A survey of perceived satisfaction with the components of FM and QoL was carried out with a sample of residents. A total of 18 FM components and five QoL domains, including physical health, independence, psychological health, social relationships and living environment, as well as overall QoL were identified.

Findings: The findings show that; (1) physical health is influenced by accessibility, doors and windows and signage; (2) independence can be improved by enhancing accessibility, water supply, lighting and ventilation; (3) accessibility, water supply, distance and doors and windows all predict psychological health; (4) social relationships are improved by lighting and ventilation; (5) distance impacts positively on living environment and (6) overall QoL is predicted by lighting, ventilation, accessibility, doors and windows, handrails, recreation and signage.

Originality/Value: The study recommends that designers and facilities managers review the micro-climate settings to harness available natural lighting and ventilation, introduce bimetallic strips to the heating systems to maintain a suitable water temperature and install large, easy to understand and graphic signage for straightforward wayfinding in C\&A homes.
\end{abstract}

Keywords: Care and Attention Homes, Elderly, Facilities Management, Quality of Life

\section{INTRODUCTION}

The worldwide elderly population is increasing significantly (United Nations 2013). The number of elderly aged 65 and older is estimated to increase from 115 million (8.5\%) in 2010 to 283 million (19.7\%) in 2035 in China (Du et al. 2005); and from 918,500 (13.1\%) in 2010 to 2.36 million (28.3\%) in 2035 in Hong Kong (Census and Statistics Department 2012). In fact, more than half of the worldwide elderly population (i.e., 54\%) lives in Asia (United Nations 2013). Their quality of life (QoL) requires in-depth consideration due to the imminent anticipated growth rate (Murphy et al. 2006).

Despite improvement in health technologies, cognitive decline and frailty makes it difficult for some elderly people to remain in their homes. Consequently, care and attention (C\&A) homes are provided to meet the special needs of the frail elderly who require long-term care and support. These elderly residents spend most of their time within the C\&A homes. Therefore, the provision of good-quality facilities is essential to safeguard their living conditions and QoL. Previous studies focus on elderly QoL (e.g., Banister and Bowling 2004; Gabriel and Bowling 2004) and satisfaction with facilities management (FM) 
components (Heng and Loosemore 2013; Leung et al. 2012, 2014; Samah et al. 2013). However, few studies have looked at the link between FM components and QoL for the elderly, particularly in the context of C\&A homes. The study therefore investigates the effect of FM components on the QoL of elderly residents in C\&A homes.

\section{C\&A HOMES IN HONG KONG}

C\&A homes are residential apartments that provide meals, personal care and limited nursing care for elderly people with poor health, physical or mild mental disabilities and impairment of activities of daily living (ADL), but who are able to live communally (Social Welfare Department 2005). The service is offered to those aged 65 years or above who need help with ADL and are unable to live at home. C\&A homes are provided through subsidies for places in subvented, self-financing and contract homes, subsidized places under the Enhanced Bought Place Scheme and non-subsidized places in non-profit-making self-financing /contract homes in Hong Kong (Social Welfare Department 2015).

In recent years, the government has promoted policies to increase the number of subsidized places for residential care in existing subsidized contract homes by purchasing vacant places from self-financing nursing homes and utilizing space in existing subsidized homes providing continuous care (Hong Kong Policy Address 2009). However, the quality of the service received by elderly residents from staff in C\&A homes has been criticized, particularly the indoor facilities and facilities management (The Standard 2015a; 2015b). Some C\&A homes allocate 5-6 elderly people into a room of $20 \mathrm{~m}^{2}$ and require 20 residents to share a $5 \mathrm{~m}^{2}$ bathroom (Leung et al. 2014). Small spaces create difficulties for elderly people with poor mobility and limit their privacy, which may affect their self-esteem and lead to negative feelings. Similarly, small bathroom spaces make it impossible to install assistive technologies for the use of the frail elderly.

\section{FM IN C\&A HOMES}

FM is defined as the coordination of the physical environment (e.g., space management and recreational facilities) and the person (i.e., elderly) to serve strategic objectives (Leung et al. 2013). In fact, understanding the interactions between space, people and process are pivotal to the effectiveness of FM in C\&A homes (Ilozor and Ilozor 2006). However, facilities in C\&A homes are varied and may affect the QoL of residents. To improve FM in C\&A homes and meet the needs of the elderly, it is necessary to properly coordinate the planning, design and management of buildings, facilities and furniture (Becker 1990). Hence, a thorough understanding of the basic facilities required in C\&A homes is critical. Based on an extensive literature review, FM components can be divided into three major categories; architecture, building services and support facilities (Leung et al. 2012).

Architecture refers to the layout and design of buildings in order to enhance the quality of the environment, which covers space, distance, colour and decoration (Cotts 1999). The layout and circulation space for the elderly should be flexible in order to meet their changing physical and psychological conditions of the Chinese elderly (Zhaoru 1997). For instance, increasing the size of bathrooms may lessen the difficulties experienced by older people when carrying out ADL such as bathing, toileting, and so on. On the other hand, elderly people residing in C\&A homes are often frail and have limited muscle strength for standing 
up in bathtub or engaging in a long walk (Etman et al. 2014). A long corridor and a simple bathtub may induce falling, and create hurdle for participating in ADL within the home (Hassanain 2010). Furthermore, a long distance between the C\&A home and public places (e.g., shopping malls, transport station, parks, etc.) may also affect opportunities for elderly social interaction and also discourage them from engaging in daily activities independently. Careful selection of colour, contrasts and decoration during building design is necessary to reduce confusion for the visually impaired elderly.

Building services are required for the effective functioning of the facility to meet the occupants' needs, including lighting, temperature, ventilation, security and the water supply (Leung et al. 2014). Visual impairment increases with age (Bosch et al. 2012). Therefore, more and better-quality lighting (natural or artificial) is needed to help compensate for the compromised vision of older residents. Similarly, a good temperature and ventilation system (natural and artificial) in the rooms allow residents to maintain the constant body temperature needed to safeguard their physical health (Windisch 2008). Due to the susceptibility of the elderly to fear of crime (Yin 1982), scanning for personal identification at the building entrance or frequent patrol by security guards may allay the fears of the elderly in the C\&A homes. On the other hand, excessively hot or cold water from showers can result in burns and cardiac strains in the elderly (Carefect Home Health Care Services 2014).

Supporting facilities help to enable the daily lives of the elderly and include items such as safety, kitchen utensils, recreational facilities, handrails, accessibility, non-slip flooring, doors and windows, hygiene and signage (Leung et al. 2013). Design features (e.g., edges of furniture, height of steps, etc.) in C\&A homes should guarantee the safety of the elderly (Carter et al. 1997), while kitchen utensils such as refrigerators are used to store food in order to avoid the infestation of bacterium causing diseases and infection. The provision of recreational facilities and parking space within or outside the C\&A homes may encourage social interactions and reduce negative feelings like depression and loneliness among Chinese residents (Zhang and Gobster 1998). Similarly, therapeutic facilities can be helpful to the disabled elderly in C\&A homes (Cooke et al. 2005). Handrails and lift bars support their mobility and ADL, while doors permit their entrance and exit within rooms in the C\&A homes. Moreover, the use of non-slip flooring in all the rooms in C\&A homes also reduce the chances of falling (Afifi et al. 2015; Leung et al. 2013). It is believed that accessibility with proper signage can reduce dependence and support self-esteem of the elderly (Wahl et al. 2007). On the other hand, windows allow lighting and ventilation needed for maintaining good health (Lau et al. 2010). Areas with good hygiene may improve both physical and psychological health of the elderly, and prevent them against infection in the home (Torrington 1996).

\section{QoL}

The need to broaden the focus of traditional concepts of health gave rise to the concept of QoL. The development of a QoL assessment embraced a holistic approach to health and care (WHO 1996). Besides personal health, QoL considers the individual's perception of his/her position in life based on goals, expectations and concerns within the context of the culture and value system of the environment (Harper and Power 1998). Hence, QoL consists of physical and psychological health, social relationships and the living environment (WHOQOL Group 1998). 
Physical health refers to the absence of sickness or illness (Veenhoven 2008), including the ability to engage in ADL and meet responsibilities that require physical action (Bowling 2005). Active participation in ADL is pivotal to good physical health (Bowling et al. 2003), but a decline in energy and mobility limits participation in such activities and makes it hard to walk long distances in C\&A homes (Egerton et al. 2009). In fact, pain is a frequent problem for about $50 \%$ of the Chinese elderly (Woo et al. 2009). Pain disturbs sleep, affects daily life and increases dependence on medical aids and substances (Cabedo and Escuder-Mollon 2013; de Andrade et al. 2011).

Independence is an important attribute to ensure the elderly autonomy (Murphy et al. 2006). Due to the declined health condition, elderly may rely on medical support for maintaining their body functions. The abilities of the elderly to move around and perform the normal ADL in the C\&A home are, thus, substantially affected (Clares et al. 2014; Kovar and Lawton 1994). Therefore, various facilities, including sufficient space for walking assisted devices, and non-slip flooring and handrails in all rooms may play essential roles for sustaining elderly daily life (Donoghue et al. 2003).

Psychological health refers to emotional reactions to life events, which can result from the subjective interpretation of individual health (Diener et al. 2003). It considers the patterns of thoughts, feelings and behaviour that differentiate one person from another. Elderly with good memory and active learning abilities normally experience positive feelings which can enhance self-esteem (Carpenter et al. 2013). In fact, accepting changes in body image and appearance is linked to satisfaction in later life (Reboussin et al. 2000). However, poor lighting and limited space for daily life activities in C\&A homes can induce negative feelings in the elderly (Kim and Kim 2010).

Social relationships involve the individual's perception of personal relationships, social roles and the need for family and social support (Diener et al. 2003). They enable an individual to feel cared for, valued and part of a network of communications and mutual obligation (Stroebe 2000). Hence, older people need to connect with members of the community and seek support from friends. Because of the cultural influence of social ties among Chinese family members (Chi and Chou 2001), common space for visiting the elderly should be provided within the C\&A home. The provision of physiotherapy equipment for recreation also creates avenues for social interaction among residents.

The living environment is one of the determinants of QoL because all the resources we use as human beings come directly from the environment (Inoguchi and Shin 2009). The relationship between people and their environment is central to the concept of QoL (Pacione 2003). Freedom, safety and security in the physical environment promote feelings of comfort among the elderly (Murphy et al. 2006). However, a living environment with appealing features and good housing facilities, as well as access to good-quality health and social care, may require the investment of huge financial resources (Bullock et al. 2008).

\section{CONCEPTUAL MODEL}

Based on an extensive review of the literature, it is hypothesized that the FM components in C\&A homes have direct relationships with aspects of the QoL of the elderly. Figure 1 shows a conceptual model of FM components (architecture, building services and supporting facilities) and elderly QoL (physical health, independence, psychological health, social 
relationships, living environment and overall QoL).

$<$ Figure $1>$

\section{RESEARCH METHOD}

A questionnaire survey of the elderly people living in C\&A homes was conducted. It had three sections: (1) background information about the respondents; (2) degree of satisfaction with QoL and (3) degree of satisfaction with FM components in C\&A homes. Based on the literature review, 18 FM components under the three main headings were identified, while the five QoL domains as well as overall QoL were adopted from the World Health Organization Quality of Life (WHOQOL) scale (see Table 1). The WHOQOL measurement scale was chosen because of its comprehensiveness (WHO 1996). In consideration of the cognitive abilities of elderly participants, the FM and QoL items were measured using numerical scores ranging from 1 (very dissatisfied) to 5 (very satisfied). The elderly in Hong Kong are predominantly (99\%) traditional Chinese who normally communicate in Chinese (Census and Statistics Department 2011). Hence, the questionnaires were translated into Chinese to eliminate any language barriers.

Four C\&A homes were purposively selected based on the following criteria; (1) building type (i.e. purpose built or non-purpose built) and (2) financing method (e.g., government or selffinanced) with one home in each sub-category. Fifteen elderly respondents were purposively selected from each C\&A home using the following criteria; (1) aged over 60 at the time of survey; (2) had lived in the home for over 3 months and (3) had the necessary cognitive ability to understand and respond to the questions. To avoid any misunderstanding of the items, the survey was completed during face-to-face individual semi-structured interviews conducted by trained interviewers. Of the 60 respondents, $45 \%$ were aged $60-69,41.7 \%$ aged $70-79$ and $13.3 \%$ aged 80 and above. Less than half (i.e. $45 \%$ ) were male, while $55 \%$ were female. Seven percent had never married, while $71 \%$ and $22 \%$ were married or widows /widowers respectively.

In order to establish the relationship between the FM components and the QoL of the elderly, reliability tests and multiple regression analysis were conducted using SPSS version 20.0. Reliability analysis was carried out to test the internal consistency of the FM components as well as the QoL domains using Cronbach's alpha values. The multiple regression analysis was conducted to test the predictive ability of the FM components on the QoL of the elderly.

\section{RESULTS}

\section{Reliability Analysis of FM Components}

Based on the literature, 61 questions were designed to measure 18 FM components (see Table 1). Eighteen FM components were identified, namely space planning (F1), distance (F2), colour and decoration (F3), lighting (F4), temperature (F5), ventilation (F6), fire service (F7), security (F8), water supply (F9), safety (F10), kitchen utensils (F11), recreational facilities (F12), handrails (F13), accessibility (F14), non-slip flooring (F15), doors and windows (F16), hygiene (F17) and signage (F18). The reliability of each FM component is shown in Table 1. All alpha values are greater than 0.7 , which confirms their internal consistency (Hair et al. 
2010).

$$
<\text { Table } 1>
$$

Using the WHOQOL scale, elderly QoL was classified into five domains, including physical health $(\mathrm{Q} 1)$, independence $(\mathrm{Q} 2)$, psychological health $(\mathrm{Q} 3)$, social relationships $(\mathrm{Q} 4)$ and living environment (Q5) as well as overall QoL (OQ). All the QoL values were reliable with a Cronbach's alpha value higher than 0.5 (see Table 2). The scores for the QoL domains and FM components were calculated by summing the ratings of relevant items.

$$
<\text { Table } 2>
$$

\section{Multiple Regression Analysis of FM Components and QoL of the Elderly}

A multiple regression analysis was conducted to test the predictive power and relative contribution of FM components to the QoL of the elderly using a stepwise method (Pallant 2011). An additional model for overall QoL was added to the five models. Model I indicates that physical health (Q1) is significantly predicted by accessibility (F14), doors and windows (F16) and signage (F18), explaining $61.1 \%$ of the variance. Model II shows that independence (Q2) is significantly influenced by accessibility (F14), water supply (F9), lighting (F4) and ventilation (F6), explaining 66.9\% of the variance. Psychological health (Q3) as seen in Model III is significantly improved by accessibility (F14), water supply (F9), distance (F2) and doors and windows (F16), explaining 65.2\% of the variance. In Model IV, social relationships $(\mathrm{Q} 4)$ is significantly predicted by lighting $(\mathrm{F} 4)$ and ventilation $(\mathrm{F} 6)$, explaining $69.4 \%$ of the variance. The living environment (Q5) in model V is significantly affected by distance (F2), explaining $48.0 \%$ of the variance. Lastly, Model VI shows that lighting (F4), ventilation (F6), accessibility (F14), doors and windows (F16), handrails (F13), recreational facilities (F12), and signage (F18) all significantly affect overall QoL (OQ), explaining $80.9 \%$ of the variance.

$$
<\text { Table } 3>
$$

\section{DISCUSSION}

The result of the multiple regression analysis show that QoL among the elderly is significantly predicted by the FM components of distance (F2), lighting (F4), ventilation (F6), water supply (F9), recreational facilities (F12), handrails (F13), accessibility (F14), doors and windows (F16) and signage (F18) (see Figure 2).

$$
<\text { Figure } 2>
$$

\section{Architecture}

It is surprising that only the distance (F2) between the rooms and facilities in the C\&A homes influences the psychological health and living environment of the elderly. The ability of the elderly to participate in physical activity through walking within and outside the home environment can induce positive feelings about their health (Hsia et al. 2013). On the other hand, the inability to engage in such activities results in low self-esteem and negative 
feelings. Elderly residents can engage in walking as a leisure /physical activity in a C\&A home with long corridors, which will help them to maintain positive feelings. However, due to low muscular strength and limited energy for walking long distances, the chances of falling or collision increase, which can cause counterbalancing negative emotions.

\section{Building Services}

It can be seen that lighting influences independence, social relationships and overall QoL; ventilation affects social relationships and overall QoL and water supply predicts the physical and psychological health of elderly. In Hong Kong, the window openings in C\&A homes are normally located on one side of the rooms, while each room may accommodate five or six residents. This significantly affects the Chinese elderly, particularly those with diverse disabilities and impairments such as dementia, visual impairment, respiratory disease, weak immunity and so on (Lee 1997). Good lighting (F4) therefore strengthens neighbourhood relationships, supports mobility and helps to maintain good health, especially at night, as well as supporting ADL. On the other hand, poor ventilation (F6) creates an atmosphere that is not conducive to gathering together for social interaction within C\&A homes. Therefore, building orientation can be harnessed to provide the natural lighting and ventilation required to maintain good QoL. In fact, large windows allow sufficient natural lighting and ventilation, which creates an atmosphere suitable for conversation and stimulates social interaction. An excessively hot water supply (F9) to the showers can expose the elderly to burns and scalds due to sensory impairment and slow reaction times (Carefect Home Health Care Services 2014). Hence, controlling the water heating system in the residential apartments will eliminates negative emotions resulting from such injuries.

\section{Supporting Facilities}

The findings also show that accessibility improves physical health, independence, psychological health and overall QoL; doors and windows affect psychological health and overall QoL; and overall QoL is influenced by recreational facilities, handrails and provision of signage. Chinese elderly like to play cards or mah-jong, while participation in social and recreational activities (F12) can improve their health in general (Chou et al. 2004). Elderly normally have reduced muscle strength and limited energy for conducting daily activities, which may cause them to fall and sustain injuries. The provision of handrails (F13) makes it easier to maintain balance and good health (Donoghue et al. 2003). In addition, weak and curvy spinal bones resulting from loss of elasticity in the ligaments makes it harder for the elderly to stand upright (Hooyman and Kiyak 2008). This affects the accessibility (F14) of items placed at standard heights for adults in general. Therefore, the height of facilities and utensils within the C\&A homes should be lowered in order to ensure they can be reached by elderly residents.

Furthermore, convenience of doors and windows (F16) can stimulate positive feelings. A convenient window allows the elderly to open /close it and regulate the natural air quality and daylight in their residential apartments, while stiff window closers and door locks discourage independence, induce negative feelings and reduce overall QoL (Garvin 1998). Moreover, the elderly have limited energy for carrying out daily activities such as opening doors. The design of door closers requiring great force results in negative feelings. Hence, doors and windows should be designed to be operated with minimal force so as to promote positive reactions in the elderly. Memory loss impairs residents' ability to find their way through the space in the home (Bissell 2010). Signage (F18) with graphics and other visual indicators 
helps the elderly find their way independently and thus improves their QoL.

\section{RECOMMENDATIONS}

The findings of this study demonstrate significantly positive relationships between certain FM components in C\&A homes and the QoL of elderly residents. Practical suggestions can be made for designers and facilities managers to enable them to provide the right facilities in C\&A homes and thus enhance the QoL of residents. Considering the decline in their physical ability, seats should be provided at strategic locations within the home for resting while walking down long corridors, especially those over 20m (Irish Wheelchair Association 2009). In addition, attention should be paid to the quality and quantity of lighting points, as the brightness and colour of lighting directly establishes an atmosphere for social interaction and eliminates fear and insecurity at night-time. Moreover, windows should be positioned on both sides of each room to improve ventilation. The study also recommends the introduction of bimetallic strips connected to the heating system to maintain water temperature within an acceptable range (Woodford 2008). To maintain good health, it is recommended that the preset water temperature should be around $43^{\circ} \mathrm{C}$ (Department of Health 2003).

It is also recommended that recreational facilities such as rooms for exercising and multipurpose activities be included in the design of C\&A homes for improving the QoL of elderly. Tubular handrails should be incorporated and provided in strategic places like the corridors and lobby, including lift bars next to beds and in public places and bathrooms /toilets to support mobility. In consideration of the decline in abilities, uneven surfaces and receding faces of risers should be removed at entrances and oblique planes (e.g., stairs) respectively to ensure accessibility. The use of automatic sliding windows and doors is also recommended for ease of use and to minimize the dependence of the elderly on carers (Garvin 1998). In fact, windows in licensed C\&A homes should be expected to have their operating parts within accessible reach ranges and also specify the amount of force for the doors and windows. Probably, a maximum force of $22 N$, as a new guideline in the US, is required for door closers for easy opening for the elderly in C\&A homes (United States Department of Justice 2010). To ensure efficient wayfinding, signage using large block letters (60-200mm), and easy to understand language with colourful and graphic visual indicators is also recommended.

\section{FURTHER RESEARCH}

Although this study presents important findings, the relatively small sample size and use of a self-report method may limit the ability to generalize and raise questions about common method variance. However, several factors were put in place to address this limitation. Firstly, the measurement scales used were selected based on an extensive literature review and statistically tested for reliability, all yielding acceptable alpha values. Secondly, all the elderly respondents had lived in the C\&A homes for over three months, and so would be expected to have a good understanding of the facilities in their living environment. Thirdly, the respondents were all aged 60 and above at the time of survey. Fourthly, they all had the cognitive ability to understand, interpret and respond to the questionnaire. For these reasons it is believed that there is no bias in the study.

This study adopted a quantitative approach using the subjective assessment of the QoL 
domains as identified by the WHO. The use of qualitative techniques such as personal interviews and site measurement can be used for cross-validation (Hussein 2009; Leung et al. 2014). Elderly residents in C\&A homes experience different types of diseases, which may affect the type of facilities they require in their living environment (Dwyer et al. 2000). Therefore, further studies may be conducted to ascertain the FM components that influence the QoL of elderly suffering from various diseases, with the adoption of disease-specific measurement scales.

Moreover, the current study has revealed the complicated relationships between the FM components and QoL of the elderly within the C\&A homes. In order to understand the holistic living environment, it is strongly recommend to carry on the study for the FM components outside the C\&A homes of the elderly, including open spaces, distance between the home and the supermarkets, shops, etc. The impact of outdoor FM components on elderly QoL will establish significant outcomes required for improving the living environment and, consequently, influence the satisfaction of the elderly with their late life in the C\&A home in the future.

\section{CONCLUSION}

Aging is fast becoming a global phenomenon. The increasing level of frailty among the elderly makes it necessary to provide them with support in C\&A homes. However, ensuring the quality of facilities in these homes is essential in maintaining their QoL. This study therefore identified 18 FM components, namely space planning, distance, colour, lighting, temperature, ventilation, safety, security, water supply, kitchen utensils, recreational facilities, handrails, accessibility, non-slip flooring, doors and windows, hygiene and signage. The QoL of elderly residents across five domains (physical health, independence, psychological health, social relationships and the living environment) as well as overall QoL was measured. The findings show that distance, lighting, ventilation, recreational facilities, accessibility, handrails, doors and windows and signage all have a positive impact on QoL for elderly residents of C\&A homes, whereas the water supply has a negative impact.

To improve the QoL of Chinese elderly residents in C\&A homes, it is suggested that designers and facilities managers provide seating at strategic locations along long corridors, review the micro-climate to harness natural lighting and ventilation, increase the quality and quantity of lighting points (including brightness and colour) to stimulate social interaction and provide valves for the automatic adjustment of the water temperature in bathrooms. Furthermore, the study also recommends the provision of recreational facilities such as exercise and multipurpose activity rooms; the installation of handrails and lift bars; the removal of uneven surfaces and receding faces of risers; the installation of automatic sliding windows and doors and the provision of large, easy to understand and graphic signage to provide efficient wayfinding.

\section{ACKNOWLEDGEMENT}

The work described in this paper was fully supported by a grant from the Research Grants Council of the Hong Kong Special Administrative Region, China (Project No.: CityU 115210). 
Effect of FM Components on the QoL of Chinese Elderly in C\&A Homes

\section{REFERENCES}

Banister, D. and Bowling, A. (2004) Quality of life for the elderly: the transport dimension. Transport Policy, 11, 105-115.

Becker, F. (1990) The Total Workplace. New York: Van Nostrand Reinhold.

Bissell, K. (2010) Designing for those with Dementia using the Principle of Wayfinding. Available http://muir.wrlc.org/bitstream/handle/10994/77/Final\%20Thesis\%20by\%20Kelly\%20 Bissell.pdf?sequence $=1$ (accessed 28 April 2015)

Bosch, S. J., Cama, R., Edelstein, E. and Malkin, J. (2012) The Application of Color in Healthcare Settings. California: The Center for Health Design.

Bowling, A., Gabriel, Z., Dykes, J., Dowding, L. M., Evans O., Fleissig, A., Banister, D. and Sutton, S. (2003) Let's ask them: a national survey of definitions of quality of life and its enhancement among people aged 65 and over. International Journal of Aging and Human Development, 56(4), 269-306.

Bullock, C., Brereton, F., O'Neill, E., Clinch, J. P. and Russell, P. (2008) Quality of Life and the Environment (Environmental RTDI Programme 2000-2006 Report). University College Dublin: Environmental Protection Agency.

Cabedo, S. and Escuder-Mollon, P. (2013) Improving Seniors' Quality of Life: A Toolkit to Evaluate Education for Elderly Learners. Available at: http://www.edusenior.eu (accessed 10 October 2014).

Carefect Home Health Care Services (2014) Bath Water Temperature Safety for the Elderly. Available at: http://www.carefecthomecareservices.com/blog/bath-water-temperaturesafety-elderly/ (accessed 11 July 2015).

Carpenter, S. M., Peters, E., Vastfjall, D. and Isen, A. M. (2013) Positive feelings facilitate working memory and complex decision making among older adults. Cognition and Emotion, 27(1), 184-192.

Carter, S. E., Campbell, E. M., Sanson-Fisher, R. W., Redman, S. and Gillespie, W. J. (1997) Environmental hazards in the homes of older people. Age and Ageing, 26, 195-202.

Census and Statistics Department (2011) Thematic Report: Older Persons. Available at: http://www.census2011.gov.hk/pdf/older-persons.pdf (accessed 5 April 2015).

Census and Statistics Department (2012) Hong Kong Population Projections 2012-2041. Available at: http://www.statistics.gov.hk/pub/B1120015052012XXXXB0100.pdf (accessed 6 April 2014).

Chi, I. and Chou, K. L. (2001) Social support and depression among elderly Chinese people in Hong Kong. International Journal of Aging and Human Development, 52(3), 231252.

Chou, K. L., Chow, N. W. S. and Chi, I. (2004) Leisure participation amongst Hong Kong Chinese older adults. Ageing and Society, 24, 617-629.

Cooke, M., Chaboyer, W. and Hiratos, M. A. (2005) Music and its effect on anxiety in short waiting periods: a critical appraisal. Journal of Clinical Nursing, 14, 145-155.

Cotts, D. G. (1999) The Facility Management Handbook ( $2^{\text {nd }}$ ed.). New York: American Management Association.

De Andrade, D. C., de Faria, J. W. V., Caramelli, P., Alvarenga, L., Galhardoni, R., Siqueira, S. R. D., Yeng, L. T. and Teixeira, M. J. (2011) The assessment and management of pain in the demented and non-demented elderly patient. Arquivos de Neuro-Psiquiatria, 69(2-B), 287-394.

Department of Health (2003) Care Homes for Older People. London: The Stationery Office.

Department of Justice (2010) 2010 ADA Standards for Accessible Design. Available at: http://www.ada.gov/regs2010/2010ADAStandards/2010ADAStandards_prt.pdf 
(accessed 31 August 2015).

Diener, E., Oishi, S. and Lucas, R. E. (2003) Personality, culture, and subjective well-being: emotional and cognitive evaluations of life. Annual Review of Psychology, 54, 403-425.

Donoghue, J., Graham, J., Gibbs, J., Lewis, S. M. and Blay, N. (2003) Validating components of a fall risk assessment instrument. International Journal of Health Care Quality Assurance, 16(1), 21-28.

Du, P., Zhai, Z., Chen, W. (2005) Zhong guo ren kou lao ning hua bai nian fa zhan qu shi. Population Research, 29(6), 90-93.

Dwyer, M., Gray, A. and Renwick, M. (2000) Factors Affecting the Ability of Older People to Live Independently. Available at: http://www.msd.govt.nz/about-msd-and-ourwork/publications-resources/ (accessed 2 December 2014).

El Ansary, A. M. and Shalaby, M. F. (2014) Evolutionary optimization technique for site layout planning. Sustainable Cities and Society, 11, 48-55.

Egerton, T., Brauer, S. G., Cresswell, A. G. (2009) Fatigue after physical activity in healthy and balance-impaired elderly. Journal of Aging and Physical Activity, 17, 89-105.

Etman, A., Kamphuis, C., Prins, R. G., Burdorf, A., Pierik, F. H. and van Lenthe, F. J. (2014) Characteristics of residential areas and transportational walking among frail and nonfrail Dutch elderly: does the size of the area matter? International Journal of Health Geographics, 13:7, 1-7.

Gabriel, Z. and Bowling, A. (2004) Quality of life from the perspectives of older people. Ageing and Society, 24, 675-691.

Hair, J. F., Black, W. C., Babin, B. J. and Anderson, R. E. (2010) Multivariate Data Analysis ( $7^{\text {th }}$ ed.). New Jersey: Prentice Hall.

Harper, A. and Power, M. (1998). Development of the World Health Organization WHOQOL-BREF quality of life assessment. Psychological Medicine, 28(3), 551-558.

Hassanain, M. A. (2010) Analysis of factors influencing office workspace planning and design in corporate facilities. Journal of Building Appraisal, 6(2), 183-197.

Health Information and Quality Authority (2008) National Quality Standards for Residential Care Settings for Older people in Ireland. Ireland: Health Information and Quality Authority.

Heng, H. K. S. and Loosemore, M. (2013) Structural holes in hospital organizations: facilities managers as intrapreneurial brokers in the tertiary health sector. Engineering, Construction and Architectural Management, 20(5), 474-487.

Ho, D. C. W., Leung, H. F., Wong, S. K., Cheung, A. K. C., Lau, S. S. Y., Wong, W. S., Lung, D. P. Y. and Chau, K. W. (2004) Assessing the health and hygiene performance of apartment buildings. Facilities, 22(3/4), 58-69.

Hong Kong Policy Address (2009) Breaking New Grounds Together. Available at: http://www.policyaddress.gov.hk/09-10/eng/docs/policy.pdf (accessed 18 August 2015).

Hong Kong Policy Address (2011) From Strength to Strength. Available at: http://www.policyaddress.gov.hk/11-12/eng/pdf/Policy11-12.pdf (accessed 19 August 2015).

Hooyman, N. R. and Kiyak, H. A. (2008) Social Gerontology: A Multidisciplinary Perspective (9th ed.). Boston: Allyn and Bacon.

Hsia, H. C., Yeh, K. Y., Tsukaguchi, H., Vandebona, U. (2013) The Study of the Relationships among Psychological Factors, Acceptable Walking Distance, and Reported Walking Distance for Shopping Trips. Proceedings of the Eastern Asia Society for Transportation Studies, 9, 273.

Hussein, A. (2009) The use of triangulation in social science research: can qualitative and quantitative methods be combined? Journal of Comparative Social Work, 4(1), 1-12. 
Ilozor, B. D. and Ilozor, D. B. (2006) Open-planning concepts and effective facilities management of commercial buildings. Engineering, Construction and Architectural Management, 13(4), 396-412.

Inoguchi, T. and Shin, D. C. (2009) The quality of life in Confucian Asia: from physical welfare to subjective well-being. Social Indicators Research, 92, 183-190.

Irish Wheelchair Association (2009) Best Practice Access Guidelines: Designing Accessible Environments. Dublin, Ireland: Irish Wheelchair Association.

Jick, T. D. (1979) Mixing qualitative and quantitative methods: triangulation in action. Administrative Science Quarterly, 24, 602-611.

Johansson, M., Rosen, M. and Kuller, R. (2011) Individual factors influencing the assessment of outdoor lighting of an urban footpath. Lighting Research and Technology, 43, 3143.

Ki-chung, M. C. (2009) LCQ7: Subsidized Care-and-attention Places (press release). Available at: http://www.info.gov.hk/gia/general/200904/01/P200904010139.htm (accessed 31 August 2015).

Kim, G. and Kim, J. T. (2010) Healthy-daylighting design for the living environment apartments in Korea. Building and Environment, 45(2), 287-294.

Lau, S. S. Y., Gou, Z. and Li, F. M. (2010) Users' perceptions of domestic windows in Hong Kong: challenging daylighting-based design regulations. Journal of Building Appraisal, 6, 81-93.

Lee, D. T. F. (1997) Residential care placement: perceptions among elderly Chinese people in Hong Kong. Journal of Advanced Nursing, 26, 602-607.

Leung, M. Y., Chan, I. Y. S. and Olomolaiye, P. (2013) Relationships between facility management, risks and health of elderly in care and attention homes. Facilities, 31(13/14), 659-680.

Leung, M. Y., Yu, J. and $\mathrm{Yu}, \mathrm{S}$. (2012) Investigating key components of the facilities management of residential care and attention homes. Facilities, 30(13), 611-629.

Leung, M. Y., Yu, J., Dongyu, C. and Yuan, T. (2014) A case study exploring FM components for elderly in care and attention homes using post occupancy evaluation. Facilities, 32 (11/12), 685 - 708.

Murphy, K., O'Shea, E., Cooney, A., Shiel, A. and Hodgins, M. (2006) Improving Quality of Life for Older People in Long-stay Care Settings in Ireland (Report No. 93). Dublin: National Council on Ageing and Older People.

Noell-Waggoner, E. (2006) Lighting in Nursing Homes - The Unmet Need. Austria: International Commission on Illumination.

Pacione, M. (2003) Urban environmental quality and human well-being - a social geographical perspective. Landscape and Urban Planning, 65, 19-30.

Pallant, J. (2011) SPSS Survival Manual: A Step by Step Guide to Data Analysis Using SPSS (4th ed.). China: Everbest Printing Company.

Rader, J., Barrick, A. L., Hoeffer, B., Sloane, P. D., McKenzie, D., Talerico, K. A. and Glover, J. U. (2006) The bathing of older adults with dementia: easing the unnecessarily unpleasant aspects of assisted bathing. American Journal of Nursing, 106(4), 40-48.

Reboussin, B. A., Rejeski, W. J., Martin, K. A., Callahan, K., Dunn, A. L., King, A. C. and Sallis, J. F. (2000) Correlates of satisfaction with body function and body appearance in middle- and older aged adults: the activity counseling trial (ACT). Psychology and Health, 15(2), 239-254.

Robson, D. G., Nicholson, A. M. and Barker, N. (1997) Homes for the Third Age: A Design Guide for Extra Care Sheltered Housing. London: E. and F.N. Spon.

Social Welfare Department (2005) Care and Attention Homes for the Elderly. Available at: 
http://www.swd.gov.hk/doc/elderly/(P16).pdf (accessed 15 July 2015).

Social Welfare Department (2015) Residential Care Services for the Elderly. Available at: http://www.swd.gov.hk/en/index/site pubsvc/page elderly/sub residentia/id overvie won/ (accessed 18 August 2015).Statistics Canada (2012) Population Count and Population Growth in Canada. Available at: http://www.statcan.gc.ca/pub/91-520x/2010001/aftertoc-aprestdm1-eng.htm (accessed 9 August 2015).

Sutherland, D., Woodward, Y., Byrne, J., Allen, H. and Burns, A. (2004) The use of light therapy to lower agitation in people with dementia. Nursing Times, 100(44), 32-34.

The Hong Kong Council of Social Service (2009) Partnership in Meeting Social Challenges (Annual Report 2009-2010). Available at: http://www.hkcss.org.hk/uploadFileMgnt/0_201343016256.pdf (accessed 6 April 2014).

The Standard (2015a, May 27) Outcry over Seniors Stripped of Dignity. Available at: http://www.thestandard.com.hk/news detail.asp?pp_cat=30\&art id=157338\&sid $=44$ 547862\&con type $=1 \& d$ str $=20150527 \&$ isSearch $=1 \&$ sear year $=2015$ (accessed 31 August 2015)

The Standard (2015b, May 28) Excuses over Naked Elders just don't Wash. Available at: http://www.thestandard.com.hk/news detail.asp?pp cat=49\&art id=157381\&sid=44 556352\&con type $=1 \& d$ str $=20150528 \&$ isSearch $=1 \&$ sear_year $=2015$ (accessed 31 August 2015).

The WHOQOL Group (1998) The World Health Organization Quality of Life (WHOQOL) assessment: development and general psychometric properties. Social Science and Medicine, 46(12), 1569-1585.

Tolman, A. and Parkkila, T. (2009) FM tools to ensure health performance based buildings. Facilities, 27(11/12), 469-479.

Torrington, J. M. and Tregenza, P. R. (2007) Lighting for people with dementia. Lighting Research and Technology, 39, 81-97.

United States Department of Justice (2010) 2010 ADA Standards for Accessible Design. United States: Department of Justice.

Veenhoven, R. (2008) Healthy happiness: effects of happiness on physical health and the consequences for preventive health care. Journal of Happiness Studies, 9(3), 449-469.

WHO (1996) WHOQOL BREF: Introduction, Administration, Scoring and Generic Version of the Assessment (field trial version). Geneva: World Health Organization.

Windisch, W. (2008) Impact of home mechanical installation on health-related quality of life. European Respiratory Journal, 32, 1328-1336.

Woo, J., Leung, J. and Lau, E. (2009) Prevalence and correlates of musculoskeletal pain in Chinese elderly and the impact on 4-year physical function and quality of life. Public Health, 123, 549-556.

Woodford, C. (2008) Thermostats. Available at: http://www.explainthatstuff.com/thermostats.html (accessed 8 July 2015).

Yin, P. (1982) Fear of crime as a problem for the elderly. Social Problems, 30(2), 240-245.

Zhang, T. and Gobster, P. H. (1998) Leisure preferences and open space needs in an urban Chinese American community. Journal of Architectural and Planning Research, 15(4), 338-355.

Zhaoru, L. (1997) Planning for the elderly in the development and construction of new residential areas in Shanghai. Cities, 14(2), 77-84. 
Table 1 Coefficient Alpha Reliabilities for FM Components

\begin{tabular}{|c|c|c|c|}
\hline FM Components & Items & Descriptions & $\alpha$-value \\
\hline \multicolumn{4}{|l|}{ Architecture } \\
\hline \multirow{6}{*}{ F1-Space planning } & 1. & Furniture spacing & 0.853 \\
\hline & 2. & Storage area & \\
\hline & 3. & Width of door & \\
\hline & 4. & Rest area in lobby & \\
\hline & 5. & Rest area in corridor & \\
\hline & 6. & Rest area in bathroom & \\
\hline \multirow[t]{6}{*}{ F2-Distance } & 7. & $\begin{array}{l}\text { Distance between bedroom and various areas such as kitchen, } \\
\text { bathroom, living room and dining room }\end{array}$ & 0.941 \\
\hline & 8. & $\begin{array}{l}\text { Distance between recreational facilities and public places } \\
\text { (e.g., shopping mall, entrance of building) }\end{array}$ & \\
\hline & 9. & Distance between transport stations and entrance of buildings & \\
\hline & 10. & Distance between shopping mall and entrance of buildings & \\
\hline & 11. & Distance to neighbourhood & \\
\hline & 12. & Distance to fire escape & \\
\hline F3-Colour and decoration & 13. & Wall colour & 0.878 \\
\hline & 14. & Floor colour & \\
\hline & 15. & Common room ornaments (e.g., pictures and plants) & \\
\hline \multicolumn{4}{|l|}{ Building services } \\
\hline F4-Lighting & $\begin{array}{l}16 . \\
17 .\end{array}$ & $\begin{array}{l}\text { Provision of natural light } \\
\text { Provision of artificial light }\end{array}$ & 0.898 \\
\hline F5-Temperature & $\begin{array}{ll}18 . \\
19 .\end{array}$ & $\begin{array}{l}\text { Indoor temperature } \\
\text { Temperature of lobby and corridor }\end{array}$ & 0.788 \\
\hline F6-Ventilation & 20. & $\begin{array}{l}\text { Natural ventilation } \\
\text { Artificial ventilation }\end{array}$ & 0.861 \\
\hline F7-Fire service & $\begin{array}{l}22 . \\
23 . \\
24 .\end{array}$ & $\begin{array}{l}\text { Fire escape } \\
\text { Firefighting devices provided } \\
\text { Emergency exit (e.g., number and distance) }\end{array}$ & 0.975 \\
\hline F8-Security & 25. & $\begin{array}{l}\text { Security guards (e.g., number, patrol times) } \\
\text { Scan before entering building }\end{array}$ & 0.750 \\
\hline F9-Water supply & $\begin{array}{l}27 . \\
28 . \\
29 .\end{array}$ & $\begin{array}{l}\text { Water flow of shower } \\
\text { Temperature of water in shower }\end{array}$ & 0.783 \\
\hline \multicolumn{4}{|l|}{ Supporting facilities } \\
\hline F10-Safety & $\begin{array}{l}30 . \\
31 . \\
32 .\end{array}$ & $\begin{array}{l}\text { Well-lit stairs } \\
\text { Height of step } \\
\text { Sharp edges of furniture or fixtures }\end{array}$ & 0.912 \\
\hline F11-Kitchen utensils & 34. & $\begin{array}{l}\text { Kitchen appliances (e.g., refrigerator, range hood) } \\
\text { Switch system of tap } \\
\text { Location and height of tap }\end{array}$ & 0.847 \\
\hline F12-Recreational facilities & $\begin{array}{l}36 . \\
37 . \\
38 . \\
39 . \\
40 . \\
41 . \\
42 .\end{array}$ & $\begin{array}{l}\text { Number of recreational facilities } \\
\text { Design of recreational facilities } \\
\text { Type of recreational facilities } \\
\text { Recreational facilities (e.g., height and width of chairs) } \\
\text { Number of parks } \\
\text { Sport facilities in park } \\
\text { Nearby long oblique plane for facilitating transportation and } \\
\text { physical exercise }\end{array}$ & 0.966 \\
\hline F13-Handrails & $\begin{array}{l}43 . \\
44 . \\
45 . \\
46 . \\
47 .\end{array}$ & $\begin{array}{l}\text { Lift bar next to bed } \\
\text { Lift bar next to public toilet (e.g., mall, parks etc.) } \\
\text { Handrail and safety lift (e.g., number, type etc.) } \\
\text { Handrail in corridor and lobby }\end{array}$ & 0.926 \\
\hline
\end{tabular}




\begin{tabular}{|c|c|c|c|}
\hline & 48. & Handrail of stairs & \\
\hline \multirow[t]{4}{*}{ F14-Accessibility } & 49. & Accessibility of entrance & \multirow[t]{4}{*}{0.881} \\
\hline & 50. & Accessibility at oblique plane (e.g., stairs) & \\
\hline & 51. & Height of stove or cabinet & \\
\hline & 52. & Height of toilet (e.g., indoor, public) & \\
\hline \multirow[t]{2}{*}{ F15-Non-slip flooring } & 53. & Slip resistance of floor finishes in kitchen & \multirow[t]{2}{*}{0.772} \\
\hline & 54. & Slip resistance of floor finishes in bathroom and/or toilet & \\
\hline \multirow[t]{3}{*}{ F16-Doors and windows } & 55 & Convenience of doors & \multirow[t]{3}{*}{0.798} \\
\hline & 56. & Convenience of windows & \\
\hline & 57. & Design of door lock & \\
\hline \multirow[t]{2}{*}{ F17-Hygiene } & 58. & Cleanliness of public areas & \multirow[t]{2}{*}{0.984} \\
\hline & 59. & Hygiene (e.g., pest control) & \\
\hline \multirow[t]{2}{*}{ F18-Signage } & 60. & Tactile signage provided (e.g., tactile markers, floor strips) & \multirow[t]{2}{*}{0.930} \\
\hline & 61. & Size of safety signs & \\
\hline
\end{tabular}


Table 2 Scale Items and Coefficient Alpha Reliabilities for QoL of the Elderly

\begin{tabular}{|c|c|c|c|}
\hline QoL Factors & Item & Description & Alpha $(\alpha)$ \\
\hline \multirow[t]{3}{*}{ Q1- Physical Health } & 1. & Pain and discomfort & \multirow[t]{3}{*}{0.596} \\
\hline & 2. & Sleep and rest & \\
\hline & 3. & Energy and fatigue & \\
\hline \multirow[t]{4}{*}{ Q2-Independence } & 4. & Mobility & \multirow[t]{4}{*}{0.919} \\
\hline & 5. & Working capacity & \\
\hline & 6. & $\mathrm{ADL}$ & \\
\hline & 7. & Dependence on medical substances and medical aids & \\
\hline \multirow[t]{5}{*}{ Q3- Psychological Health } & 8. & Thinking, learning, memory and concentration & \multirow[t]{5}{*}{0.870} \\
\hline & 9. & Self esteem & \\
\hline & 10. & Body image and appearance & \\
\hline & 11. & Positive feelings & \\
\hline & 12. & Spiritual /religion /personal beliefs & \\
\hline \multirow[t]{2}{*}{ Q4- Social Relationships } & 13. & Social support & \multirow[t]{2}{*}{0.562} \\
\hline & 14. & Personal relationships & \\
\hline \multirow[t]{8}{*}{ Q5- Living Environment } & 15. & Financial resources & \multirow[t]{8}{*}{0.720} \\
\hline & 16. & Home environment & \\
\hline & 17. & Opportunities for acquiring new information and skills & \\
\hline & 18. & Transport & \\
\hline & 19. & Freedom, physical safety and security & \\
\hline & 20. & Physical environment & \\
\hline & 21. & Health and social care: availability and quality & \\
\hline & 22. & Participation in and opportunities for recreation and leisure & \\
\hline \multirow[t]{2}{*}{ OQ- Overall QoL } & 23. & General health & \multirow[t]{2}{*}{0.867} \\
\hline & 24. & QoL & \\
\hline
\end{tabular}


Table 3 Multiple Regression Analysis Model for FM Components and QoL of the Elderly

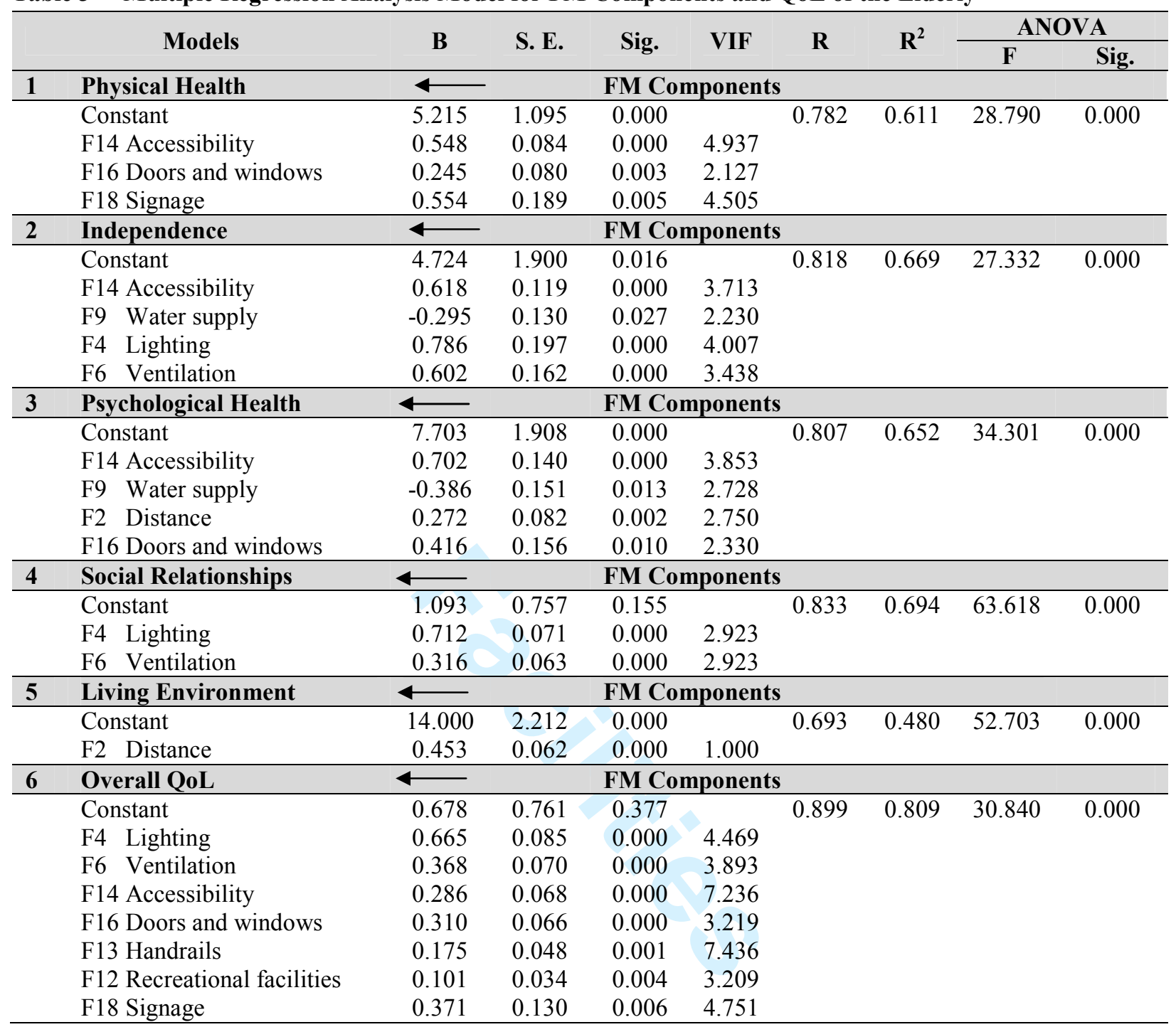

Note: S. E. = standard error; Sig. = significance; VIF = variance inflation factor 
FM Components in C\&A homes Architecture; Building services;

Supporting facilities

\section{QoL of the Elderly}

QoL Domains (Physical Health; Independence; Psychological Health; Social Relationships; Living Environment) Overall QoL

Figure 1 Conceptual Model for FM in C\&A Homes and Elderly QoL 


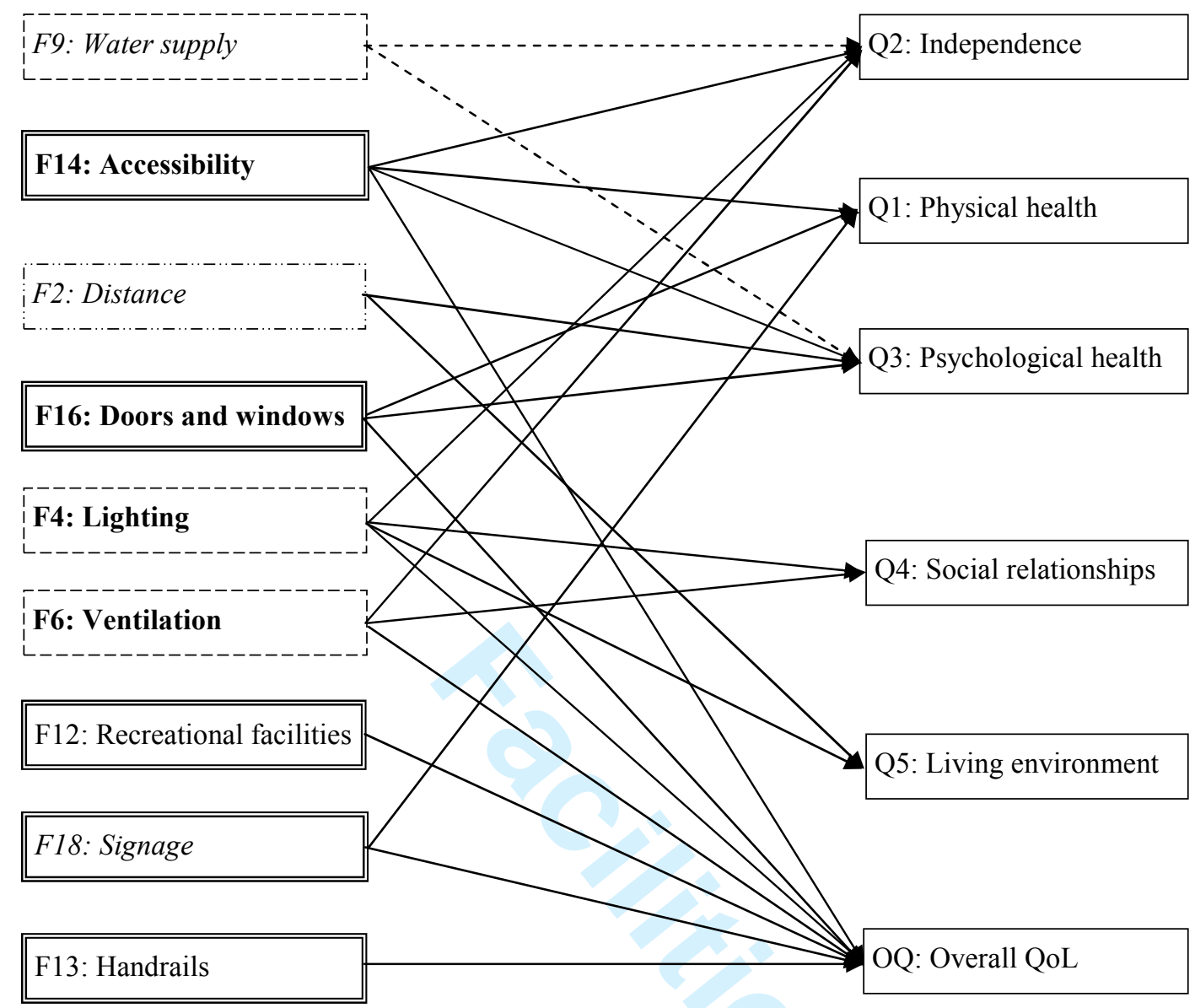

Figure 2 Relationships between FM Components and Elderly QoL in C\&A Homes

$\longrightarrow$ represents positive relationship shown in regression

$-\cdots$ represents negative relationship shown in regression

$\ddot{L} \cdots-\cdots\urcorner$ : represents architecture components

—ーーーー represents building services components

represents supporting facilities components

Bold FM components affect three or more QoL domains

Italicized FM components affect two QoL domains 


\section{EFFECT OF FACILITIES MANAGEMENT COMPONENTS ON THE QUALITY OF LIFE OF CHINESE ELDERLY IN CARE AND ATTENTION HOMES (ref.: F-03-2016-0032)}

Further to your e-mail dated $15^{\text {th }}$ June 2016 regarding the captioned paper, we have amended the paper according to the reviewers' comments. A summary of our responses to these comments is listed as below.

\begin{tabular}{|c|c|c|}
\hline \multirow{2}{*}{\multicolumn{2}{|c|}{$\begin{array}{l}\text { Reviewer's comments } \\
\text { Reviewer } 1\end{array}$}} & Responses \\
\hline & & \\
\hline 1 & $\begin{array}{l}\text { The statements concerning the } \\
\text { positive feelings of the resident being } \\
\text { able to open their own window are } \\
\text { important, given the window } \\
\text { manufacturers' and architects' } \\
\text { negative reaction to that requirement. }\end{array}$ & Thank you for the information and the comment. \\
\hline \multirow[t]{5}{*}{2} & $\begin{array}{l}\text { Literature: Each of the seventeen FM } \\
\text { components were adequately } \\
\text { footnoted to show widespread } \\
\text { understanding, but nothing was } \\
\text { mentioned about outdoor activities. }\end{array}$ & $\begin{array}{l}\text { Revised 'FM in C\&A Homes' section (see page 3) } \\
\text { Architecture refers to the layout and design of buildings in order to enhance the } \\
\text { quality of the environment, which covers space, distance, colour and } \\
\text { decoration (Cotts 1999)... A A long corridor and a simple bathtub may induce } \\
\text { falling, and create hurdle for participating in ADL within the home } \\
\text { (Hassanain 2010). Furthermore, a long distance between the C\&A home and } \\
\text { public places (e.g., shopping malls, transport station, parks, etc.) may also } \\
\text { affect opportunities for elderly social interaction and also discourage them } \\
\text { from engaging in daily activities independently. Careful selection of colour, } \\
\text { contrasts and decoration during building design is necessary to reduce } \\
\text { confusion for the visually impaired elderly. }\end{array}$ \\
\hline & & $\begin{array}{l}\text { Building services are required for the effective functioning of the facility to } \\
\text { meet the occupants' needs, including lighting, temperature, ventilation, } \\
\text { security and the water supply (Leung et al. 2014)..... Similarly, a good } \\
\text { temperature and ventilation system (natural and artificial) in the rooms allow } \\
\text { residents to maintain the constant body temperature needed to safeguard their } \\
\text { physical health (Windisch 2008). Due to the susceptibility of the elderly to } \\
\text { fear of crime (Yin 1982), scanning for personal identification at the building } \\
\text { entrance or frequent patrol by security guards may allay the fears of the } \\
\text { elderly in the C\&A homes. On the other hand, excessively hot or cold water } \\
\text { from showers can result in burns and cardiac strains in the elderly (Carefect } \\
\text { Home Health Care Services 2014). }\end{array}$ \\
\hline & & $\begin{array}{l}\text { Supporting facilities help to enable the daily lives of the elderly and include } \\
\text { items such as safety, kitchen utensils, recreational facilities, handrails, } \\
\text { accessibility, non-slip flooring, doors and windows, hygiene and signage } \\
\text { (Leung et al. 2013)...... The provision of recreational facilities and parking } \\
\text { space within or outside the C\&A home may encourage social interaction and } \\
\text { reduce negative feelings like depression and loneliness. Similarly, } \\
\text { therapeutic facilities can be helpful to the disabled elderly in C\&A homes } \\
\text { (Cooke et al. 2005). }\end{array}$ \\
\hline & & Revised ‘Further Research’ section (see page 9) \\
\hline & & $\begin{array}{l}\text { "Moreover, the current study has revealed the complicated relationships } \\
\text { between the FM components and OoL of the elderly within the C\&A homes. }\end{array}$ \\
\hline
\end{tabular}


Research methods: Is the paper limited to fifteen elderly Chinese in each of four C\&A homes in Hong Kong? Shouldn't the title indicate that limitation? distances within the room and in the common areas is appropriate and all contributing FM components are given proper credit.

5 Implications: I think the two times windows are brought up to stimulate positive feelings are important. New windows in US licensed homes are now required to have their operating parts within accessible reach ranges and with a maximum force to operate. Too often designers want this requirement ignored and expect the caregiver to open the window which decreases the independence of the residents.
4 Results: I think the emphasis on

In order to understand the holistic living environment, it is strongly recommended to carry on the study for the FM components outside the $C \& A$ homes of the elderly, including open spaces, distance between the home and the supermarkets, shops, etc. The impact of outdoor FM components on elderly QoL will establish significant outcomes required for improving the living environment and, consequently, influence the satisfaction of the elderly with their late life in the C\&A home in the future.'

Revised 'Title' (see page 1)

'Effect of Facilities Management Components on the Quality of Life of Chinese Elderly in Care and Attention Homes'

Thank you for the comment

The authors are grateful for the comments of the reviewer. In fact, the comment has been helpful in improving the recommendation in this study.

Revised 'Recommendation' section (see page 8)

'It is also recommended that recreational facilities such as rooms for exercising and multipurpose activities be included in the design of C\&A homes for improving the QoL of elderly..... The use of automatic sliding windows and doors is also recommended for ease of use and to minimize the dependence of the elderly on carers (Garvin 1998). In fact, windows in licensed $C \& A$ homes should be expected to have their operating parts within accessible reach ranges and also specify the amount of force for the doors and windows. Probably, a maximum force of $22 \mathrm{~N}$, as new requirement in US, is required for door closers for easy opening for the elderly in C\&A homes (United States Department of Justice 2010). To ensure efficient wayfinding, signage using large block letters $(60-200 \mathrm{~mm})$, and easy to understand language with colourful and graphic visual indicators is also recommended.'

6 Quality of communication: Paper reads Thank you for the comment easily and relates the physical environment to the needs of the residents' QoL separate from fire safety.

\section{Reviewer 2}

7 Separate your Literature Review from Refer to 'Introduction' section (see pages 1-2) introduction and include some more reviews of quality papers in the related field.
'The worldwide elderly population is increasing significantly (United Nations 2013). The number of elderly aged 65 and older is estimated to increase from 115 million (8.5\%) in 2010 to 283 million (19.7\%) in 2035 in China (Du et al. 2005); and from 918,500 (13.1\%) in 2010 to 2.36 million (28.3\%) in 2035 in Hong Kong (Census and Statistics Department 2012)......

'Despite improvement in health technologies, cognitive decline and frailty makes it difficult for some elderly people to remain in their homes. Consequently, care and attention (C\&A) homes are provided to meet the special needs of the frail elderly who require long-term care and support. These elderly residents spend most of their time within the C\&A homes. Therefore, the provision of good-quality facilities is essential to safeguard their living conditions and QoL. Previous studies focus on elderly QoL (e.g., Banister and Bowling 2004; Gabriel and Bowling 2004) and satisfaction with facilities management (FM) components (Heng and Loosemore 2013; Leung et al. 2012, 2014; Samah et al. 2013). However, few studies have looked at the link between FM components and QoL for the elderly, particularly in the context of C\&A homes. The study therefore investigates the effect of FM components on the QoL of elderly residents in C\&A homes.'

Revised 'FM in C\&A Homes' section (see pages 2-3)

'Architecture refers to the layout and design of buildings in order to enhance the quality of the environment, which covers space, distance, colour and decoration (Cotts 1999). The layout and circulation space for the elderly 
should be flexible in order to meet their changing physical and psychological condition (El Ansary and Shalaby 2014). For instance, increasing the size of bathrooms may lessen the difficulties experienced by older people when carrying out ADL such as bathing, toileting, and so on. On the other hand, elderly people residing in $C \& A$ homes are often frail and have limited muscle strength for standing up in the bathtub or engaging in a long walk (Etman et al. 2014). A long corridor and a simple bathtub may induce falling and create hurdle for participating in various activities or even ADL within the home (Hassanain 2010). In addition, careful selection of colour, contrasts and decoration during building design will reduce confusion for the visually impaired elderly'.

'Building services are required for the effective functioning of the facility to meet the occupants' needs, including lighting, temperature, ventilation, security and the water supply (Leung et al. 2014).... Similarly, a good temperature and ventilation system (natural and artificial) in the rooms allow residents to maintain the constant body temperature needed to safeguard their physical health (Windisch 2008). Due to the susceptibility of the elderly to fear of crime (Yin 1982), scanning for personal identification at the building entrance or frequent patrol by security guards may allay the fears of the elderly in the C\&A homes. On the other hand, excessively hot or cold water from showers can result in burns and cardiac strains in the elderly (Carefect Home Health Care Services 2014).'

'Supporting facilities help to enable the daily lives of the elderly and include items such as kitchen utensils, recreational facilities, handrails, accessibility, non-slip flooring, doors and windows, hygiene and signage (Leung et al. 2013). Design features (e.g., edges of the furniture, height of steps, etc.) in $C \& A$ homes should guarantee the safety of the elderly (Carter et al. 1997); kitchen utensils such as refrigerators are used to store food in order to avoid the infestation of bacterium causing diseases and infection......... Handrails and lift bars support their mobility and ADL, while doors permit entrance and exit within rooms in the $C \& A$ homes. Moreover, the use of non-slip flooring in all the rooms in C\&A homes also reduce the chances of falling (Afifi et al. 2015; Leung et al. 2013). It is believed that accessibility with proper signage can reduce dependence, support self-esteem and promote social interaction among elderly (Wahl et al. 2007). On the other hand, windows allow lighting and ventilation needed for maintaining good health (Lau et al. 2010). Areas with good hygiene may improve both physical and psychological health of the elderly, and prevent them against infection in the home (Torrington 1996).'

Revised 'QoL' section (see page 4)

'Independence is an important attribute to ensure the elderly autonomy (Murphy et al. 2006). Due to the declined health condition, elderly rely on medical support to maintain their body functions (Pergolizzi et al. 2008). The abilities of the elderly to move around and perform the normal ADL in the C\&A home are, thus, substantially affected (Clares et al. 2014; Kovar and Lawton 1994). Therefore, various facilities, including sufficient space for walking assisted devices, and non-slip flooring and handrails in all rooms may play essential roles for sustaining elderly daily life (Donoghue et al. 2003).'

'Psychological health refers to emotional reactions to life events, which can result from the subjective interpretation of individual health (Diener et al. 2003). It considers the patterns of thoughts, feelings and behaviour that differentiate one person from another....... In fact, accepting changes in body image and appearance is linked to satisfaction in later life (Reboussin et al. 2000). However, poor lighting and limited space for daily life activities in C\&A homes can induce negative feelings in the elderly (Kim and Kim 2010).'

We believe that the above response is sufficient at present and all the editor's comments have been treated. Please don't hesitate to contact me at any time should you have any queries. I look forward to receiving your positive response at the earliest convenience. 


\section{Page 23 of 23}

\section{Facilities}

Yours faithfully,

Mei-yung LEUNG
Encl. - A paper entitled "Effect of Facilities Management Components on Elderly Quality of Life in Care and Attention
Homes".

1

2

3

4

5

6

7

8

9

10

11

12

13

14

15

16

17

18

19

20

21

22

23

24

25

26

27

28

29

30

31

32

33

34

35

36

37

38

39

40

41

42

43

44

45

46

47

48

49

50

51

52

53

54

55

56

57

58

59

60 